\title{
Comparative study of the effect of atorvastatin and garlic extract in experimentally induced hypercholesterolemia in rabbits
}

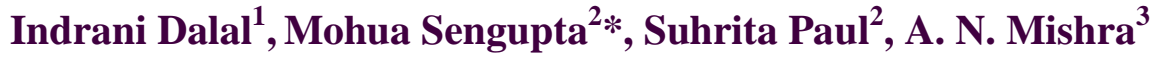

\begin{abstract}
${ }^{1}$ Department of Pharmacology, Midnapore Medical College, Kolkata, India

${ }^{2}$ Department of Pharmacology, Medical College, Kolkata, India ${ }^{3}$ Department of Pharmacology, MGM Medical College, Jamshedpur, India
\end{abstract}

Received: 27 April 2013 Accepted: 10 May 2013

\section{*Correspondence to:}

Dr. Mohua Sengupta,

Email:

senguptamohua@yahoo.co.in

(C) 2013 Dalal I et al. This is an open-access article distributed under the terms of the Creative Commons Attribution License, which permits unrestricted use, distribution, and reproduction in any medium, provided the original work is properly cited.

\begin{abstract}
Background: The abundant resource of drugs and its beneficial properties are hidden in our natural and Indigenous sources, which are under constant evaluation by man. Cholesterol lowering ability of ethanol extract of garlic was evaluated in comparison to atorvastatin, the most frequently used lipid lowering agent in rabbits.

Methods: Hypercholesterolemia was induced to the animals with cholesterol powder $(50 \mathrm{mg} / \mathrm{kg})$ for the study duration (16 weeks). At the end of 4 weeks, they were randomly selected and divided into 3 groups $(n=6)$. Group II received Cholesterol + atorvastatin $10 \mathrm{mg}$ daily; Group III received Cholesterol $+0.1 \mathrm{~g}$ garlic extract $\mathrm{kg} \mathrm{b}$. w. daily while Group I continued with cholesterol powder (to serve as control) for the rest study period. Serum cholesterol, LDL, HDL and Triglycerides were estimated using the enzymatic method at 0, 4, 8, 12, 16 weeks in all the groups. The results were tabulated and analyzed statistically using one way ANOVA test.

Results: The results indicate that both atorvastatin and garlic extract have a definite role in retarding the rate of weight gain as a consequence to high cholesterol diet in rabbits. Also, there is fewer rises in all the lipid parameters in both the treatment groups when compared to the control group.

Conclusion: Though atorvastatin is definitely more effective in reducing the lipid parameters but it also significantly lowers HDL where as Garlic shows promising results when compared to placebo and also has a favourable effect on HDL. Garlic can be recommended as a dietary supplement for long term use without toxic effects for its wide range of medicinal properties in general and therapeutic potential inpatients with $\mathrm{CAD}$ in particular.
\end{abstract}

Keywords: Hypercholesterolemia, Garlic, Atorvastatin

\section{INTRODUCTION}

The consistent observation that human atherosclerosis is prominent in clinical states accompanied by hypercholesterolemia have strongly implicated cholesterol as an important etiological agent in the development of atherosclerosis (Brodia et al 1978) ${ }^{1}$ and associated conditions like coronary artery disease, ischemic cerebrovascular diseases etc. A triangular relationship between high fat diet, blood cholesterollipoprotein levels and coronary heart disease has been established since a long time (WHO 1982). ${ }^{2}$ Among the lipoproteins, LDL cholesterol has been found to be directly associated with CHD (Gordon et al, 1977). ${ }^{3}$
Many drugs are used in the treatment of hypercholesterolemia of which the statins are most frequently prescribed. Statin-mediated lowering of lowdensity lipoprotein cholesterol (LDL -C) is regarded as the foundation of lipid-modifying therapy. However, this has failed to reduce cardiovascular event rates by more than about $20 \%-40 \%$ relative to placebo (Kastelein et al, $2005)^{4}$ indicating the need for therapeutic intervention against other lipid targets as well as non-lipid risk factors. Moreover, the potential side effects limit long term use of these drugs. Lifestyle modification and pharmacological measures must be taken together to achieve the target. In recent years there is ongoing search for natural substances that can combat hypercholesterolemia. Folic 
acid, L-carbinitine, red wine, green tea, and garlic have shown promising results. Of these, garlic (Allium sativum) gets particular attention in Modern Medicine because it has high concentration of thiosulfinates, including allicin that appears to be the active principle. This and other related substances inhibit HMG Co-A reductase involved in cholesterol biosynthesis and prevents significant rise of serum cholesterol and also increases fibrinolytic activity in patients of $\mathrm{CHD} .{ }^{3}$ The present study was undertaken to evaluate the cholesterol lowering ability of ethanol extract of garlic in comparison to atorvastatin, the most frequently used lipid lowering agent in experimental animal model (rabbit).

\section{METHODS}

\section{Animals}

Rabbit has been used as experimental animal in studies related to hypercholesterolemia and subsequent atherosclerosis since 1913 (Anitschkow et al, 1913). Healthy male rabbits weighing between $1-1.25 \mathrm{~kg}, 6$ months to 1 year of age were used for this experiment. The rabbits were kept in individual polysulfone cage with wire mesh bottom. They received normal diet containing Bengal gram, green grass, one tea spoonful maize flower and drinking water at libitum. The temperature was maintained at $22-26^{\circ} \mathrm{C}$ while the relative humidity was $50-60 \%$. The experiment was conducted in the Department of Pharmacology, MGM Medical College \& Hospitals, Jamshedpur in collaboration with Department of Pharmacology, Medical College, Kolkata. The experiments were performed following approval by the Institutional Animal Ethics Committee.

\section{Drugs and Chemicals}

Cholesterol powder

Olive oil

Atorvastatin-10mg (Lupin)

Ethanol extract of garlic

\section{Preparation of Ethanol extract of Garlic}

300 gm of wet minced garlic was kept in a two liter flask containing one liter pure ethanol for 48 hours. During this period the flask was shaken occasionally to ensure thorough extraction. Then the solvent (ethanol) was removed on a rotatory evaporator at a temperature of $40^{\circ} \mathrm{C}$ under vacuum and oily extract remaining in the flask was made moisture free and kept in a dessicator at $4^{\circ} \mathrm{C}$. The ethanolic extract yielded $46.9 \mathrm{mg}$ oil per gram of raw garlic. The rabbits were given $0.1 \mathrm{~g}$ extract per $\mathrm{kg}$ body weight per day in $1 \mathrm{ml}$ olive oil.

\section{Procedure}

All the rabbits $(n=18)$ received normal diet for pre experimental period of 4 weeks for adaptation. At the end of this period, animals were weighed, and fasting blood samples were taken from the marginal ear vein for estimation of serum lipids.

Total experimental period of study was 16 weeks. Hypercholesterolemia was induced to the animals by feeding them with cholesterol powder $50 \mathrm{mg} / \mathrm{kg}$ dissolved in $5 \mathrm{ml}$ of olive oil daily for the whole duration of study (16 weeks). At the end of 4 weeks, they were randomly selected and divided into 3 groups $(n=6)$. Group II received Cholesterol + atorvastatin $10 \mathrm{mg}(10 \mathrm{mg}$ tablets were powdered and mixed with $5 \mathrm{ml}$ of glycerine and fed with the help of a cannula to the animals) daily; Group III received Cholesterol $+0.1 \mathrm{~g}$ garlic extract per $\mathrm{kg}$ body weight per day in $1 \mathrm{ml}$ olive oil and Group I continued with cholesterol powder (to serve as control) for the rest study period of 12 weeks. After the end of study, all the drugs were withdrawn, and the rabbits were kept on normal diet for a convalescent period of six months before considering them for any other study.

Serum cholesterol, LDL, HDL and Triglycerides were estimated using the enzymatic method at $0,4,8,12,16$ weeks in all the groups. The results were tabulated and analyzed statistically using one way ANOVA test.

\section{RESULTS}

There was a steady weight gain in the rabbits of all the groups as they were fed with cholesterol diet. The increase was less in Group II and Group III in comparison to Group I, although Group II \& III were comparable (Table 1). There was a steady rise in all the lipid parameters in Group I, II and III but the rise was significantly less in treatment groups II \& III. Comparing Group II and III, atorvastatin more effectively reduced the cholesterol, LDL, TG levels than garlic extract while the HDL level was more in Group III.

Table 1: Mean body weight $(0,4,8,12 \& 16$ weeks) of the groups I, II, III (n=6).

\begin{tabular}{|lllllll|}
\hline & \multicolumn{5}{c|}{ weight in grams ( mean \pm SD) } \\
\cline { 2 - 6 } & $\mathbf{0}$ & $\mathbf{4}$ & $\mathbf{8}$ & $\mathbf{1 2}$ & 16 \\
\hline Group I & $1150 \pm 70.36$ & $1204 \pm 74.13$ & $1281.6 \pm 53.97$ & $1323.3 \pm 45.44$ & $1365.8 \pm 56.46$ \\
\hline Group II & $1137 \pm 69.49$ & $1152 \pm 70.31$ & $1176 \pm 73.93$ & $1204 \pm 74.11$ & $1226 \pm 73.27$ \\
\hline Group III & $1141 \pm 47.33$ & $1157 \pm 59.6$ & $1186 \pm 57.9$ & $1219 \pm 58.8$ & $1243 \pm 71.1$ \\
\hline
\end{tabular}


Table 2: Lipid profile for 16 weeks in experimentally produced hypercholesterolemia in rabbits.

\begin{tabular}{|lllll|}
\hline Garlic pearls & Cholesterol & LDL & TG & HDL \\
\hline Baseline & $46.6 \pm 3.08$ & $26.01 \pm 3.59$ & $37.7 \pm 4.8$ & $11.6 \pm 1.3$ \\
\hline 4weeks & $89.8 \pm 6.98$ & $53.84 \pm 2.6$ & $37.7 \pm 4.8$ & $23.9 \pm 2.9$ \\
\hline 8 weeks & $119.6 \pm 3.8$ & $65.93 \pm 6.1$ & $67.7 \pm 4.1$ & $32.1 \pm 4.8$ \\
\hline 12 weeks & $135.9 \pm 4.8$ & $78.4 \pm 4.5$ & $77.2 \pm 3.9$ & $39.3 \pm 5.1$ \\
\hline 16 weeks & $148.1 \pm 5.4$ & $91.9 \pm 3.9$ & $89.22 \pm 5.19$ & $41.4 \pm 3.2$ \\
\hline P value & $<0.0001$ & $<0.0001$ & $<0.0001$ & 0.61 \\
\hline
\end{tabular}

Table 3: Effects on the lipid profile of Atorvastatin $2 \mathrm{mg}$ for 16 weeks in experimentally produced hypercholesterolemia in rabbits $(n=6)$.

\begin{tabular}{|lllll|}
\hline $\begin{array}{l}\text { Ator } 2 \mathrm{mg}+\text { Chol } \\
\text { powder }\end{array}$ & Cholesterol & LDL & TG & HDL \\
\hline Baseline & $47.5 \pm 3.08$ & $25.08 \pm 3.59$ & $33.7 \pm 4.8$ & $12.6 \pm 1.3$ \\
\hline 4weeks & $93.1 \pm 6.98$ & $48 \pm 6.2$ & $57.7 \pm 4.1$ & $24.9 \pm 12.9$ \\
\hline 8 weeks & $110.6 \pm 4.11$ & $57.12 \pm 3.4$ & $65.88 \pm 5.4$ & $30.3 \pm 3.8$ \\
\hline 12 weeks & $122.3 \pm 4.9$ & $63.7 \pm 4.6$ & $76.9 \pm 6.2$ & $33.2 \pm 4.1$ \\
\hline 16 weeks & $137.1 \pm 3.1$ & $68.6 \pm 5.2$ & $83.4 \pm 4.33$ & $37.9 \pm 6.3$ \\
\hline P value & $<0.0001$ & $<0.0001$ & $<0.0001$ & 0.93 \\
\hline
\end{tabular}

Table 4: Effects on the lipid profile of garlic pearls in experimentally produced hypercholesterolemia in rabbits $(n=6)$.

\begin{tabular}{|lllll|}
\hline Garlic pearls & Cholesterol & LDL & TG & HDL \\
\hline Baseline & $46.6 \pm 3.08$ & $26.01 \pm 3.59$ & $37.7 \pm 4.8$ & $11.6 \pm 1.3$ \\
\hline 4weeks & $89.8 \pm 6.98$ & $53.84 \pm 2.6$ & $67.7 \pm 4.1$ & $23.9 \pm 2.9$ \\
\hline 8 weeks & $119.6 \pm 3.8$ & $65.93 \pm 6.1$ & $77.2 \pm 3.9$ & $32.1 \pm 4.8$ \\
\hline 12 weeks & $135.9 \pm 4.8$ & $78.4 \pm 4.5$ & $89.22 \pm 5.19$ & $39.3 \pm 5.1$ \\
\hline 16 weeks & $148.1 \pm 5.4$ & $91.9 \pm 3.9$ & $98.67 \pm 6.2$ & $41.4 \pm 3.2$ \\
\hline P value & $<0.0001$ & $<0.0001$ & $<0.0001$ & 0.61 \\
\hline
\end{tabular}

\section{DISCUSSION}

Sedentary life style, urbanization, industrialization, alcohol, cigarette smoking etc increases the incidence of hypercholesterolemia and consequently atherosclerosis and CHD. So attempts are being made to find safe and effective drugs and dietary factors that would lower blood cholesterol levels. All the currently available hypolipidaemic drugs have significant side effects and potential toxicities without defined benefits. They should be reserved for patients with familial hyperlipidemia or others at elevated risk of CHD. Even in these patients the drug should be discontinued after one to two months if the conc. of cholesterol is not reduced by at least an 
additional $10 \%$ of the value achieved by dietary modification alone (Hunninghake et al, 1977). ${ }^{6}$

The statins (atorvastatin, rosuvastatin, lovastatin, simvastatin etc) are a class of hypolipidaemic drugs that act by inhibiting HMG Co-A reductase, the rate limiting enzyme in the mevalonate pathway of cholesterol biosynthesis. Inhibition of this enzyme in the liver stimulates LDL receptor resulting in an increased clearance of LDL from blood and decrease in cholesterol level by $30-50 \%$. They also reduce the TG level but the rise of HDL level is less than fibrates and nicotinic acid (other hypolipidaemic drugs). The NCEP Guidelines, 2001 state that diet and lifestyle modification should be followed before staring statins or any other hypolipidaemic agents. ${ }^{7}$ Various studies like the Scandinavian Simvastatin survival study (4S) indicate that statins were useful in secondary prevention of cardiovascular diseases like Coronary artery disease, Myocardial infarction, stroke \& peripheral artery disease and also in primary prevention only when the risk for cardiovascular disease was significantly high. However, the statins are not free from adverse effects. While some patients on statins report myalgia, muscle cramps and G.I. Symptoms, the major safety concern is myositis and rarely rhabdomyolysis (pathological breakdown of skeletal muscles) which leads to acute renal failure. The risk of myopathy and rhabdomyolysis increases in proportion to the plasma Statin concentration (Omar et al, 2001). ${ }^{9}$

Garlic has acquired a reputation in the folklore of many cultures over centuries as a formidable prophylactic and therapeutic medicinal agent. The medicinal properties of garlic are mentioned frequently in the old medicinal books (Warren, 1970). ${ }^{10}$ The Spanish Pharmacopeia of 1954 listed garlic among the drugs (Hindjo et al, 1968). ${ }^{11}$

Garlic has attracted particular attention in modern medicine due to its wide range of medicinal properties for its antibacterial to anticancer effects (Srivastava et al, 1995 and Barness et al, 2002). ${ }^{12,13}$ It has hypolipidemic (Brodia et al, 1981) ${ }^{14}$ antithrombotic (Ali et al, 1995) ${ }^{15}$ and anti-atherosclerotic ${ }^{16}$ and hepatoprotective activity. It has high concentration of thiosulfinates that is responsible for reduction of risk factors of cardiovascular disease and cancer particularly of stomach and colon cancer. Bordia et al showed that garlic has a very significant protective action against hyperlipemia and blood coagulation changes. ${ }^{16}$ Sainani et al have found that the individuals who totally avoid taking garlic and onion have significantly high level of serum cholesterol, triglycerides, bola-lipoproteins and phospholipids, and those consuming small amounts of garlic and onion were better protected. ${ }^{18}$

The root bulb of garlic plant is used for medicinal purpose. Medicinally used garlic oil consists of diallyl (57\%), allyl methyl $(37 \%)$ \& dimethyl $(6 \%)$ mono to hexa sulphides (Koch et al, 1996). ${ }^{19}$ Many randomized clinical trials have studied the effect of garlic on lipid levels. Results from two Meta analysis conducted in 1993 by Warshafsky et $\mathrm{al}^{20}$ and in 1994 by Silagy et $\mathrm{al}^{21}$ on the effect of garlic on total cholesterol show a significant reduction in total cholesterol level (9-12\% when compared with placebo). A more recent trial by Ackerman et al in 2001 is a placebo controlled trial using standardized dried garlic powder which shows significant reduction in total cholesterol levels $(19.2 \mathrm{mg} / \mathrm{dl})$, LDL level $(6.7 \mathrm{mg} / \mathrm{dl})$ triglyceride level $(21.1 \mathrm{mg} / \mathrm{dl})$ in $8-12$ weeks. $^{22}$

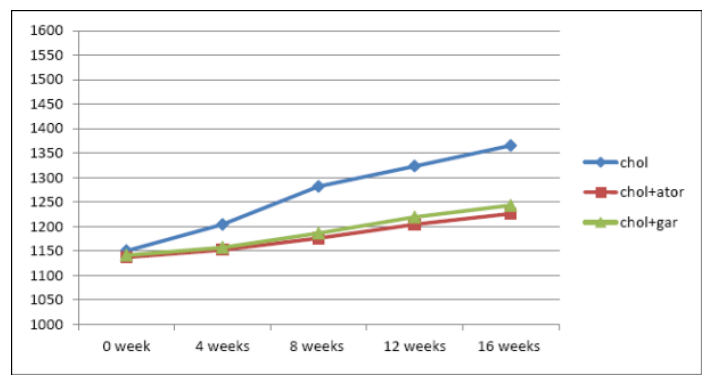

Figure 1: Showing the mean increase in body weight in the three groups.

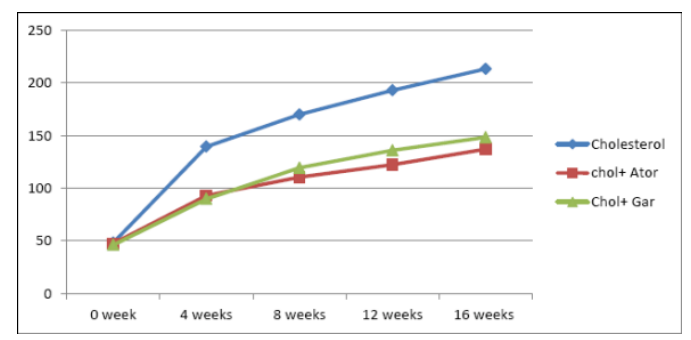

Figure 2: Showing the cholesterol level in the three groups for 16 weeks.

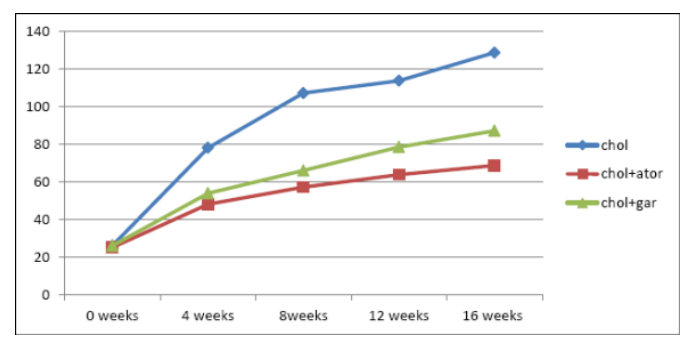

Figure 3: Showing the LDL value in the three groups for 16 weeks.

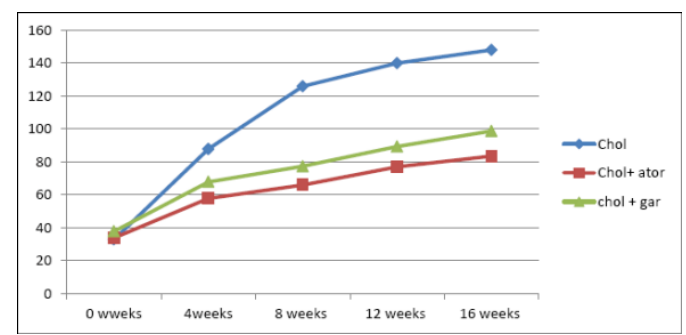

Figure 4: Showing the TG value in the three groups for 16 weeks. 


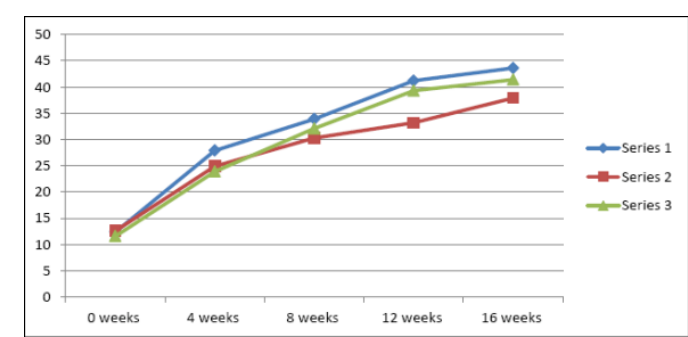

Figure 5: Showing the HDL value in the three groups for 16 weeks.

The results of the study indicate that both atorvastatin and garlic extract have a definite role in retarding the rate of weight gain as a consequence to high cholesterol diet in rabbits (Figure 1). Also, there is fewer rises in all the lipid parameters in both the treatment groups when compared to the control group. The results of the study corroborates with that of Carrol ( 1971) who have seen the plasma cholesterol levels and liver cholesterol biosynthesis in rabbits fed on commercial or semi synthetic diet with or without added fat or oils. ${ }^{23}$ When compared to garlic extract, atorvastatin is definitely more effective in reducing the lipid parameters but it also significantly lowers the good cholesterol, i.e. HDL. Though Garlic is less efficacious than atorvastatin, it shows promising results when compared to placebo and also has a favourable effect on HDL. Garlic is commonly used as food additive and can be recommended as a dietary supplement for long term use without toxic effects. It has the added advantage of having wide range of medicinal properties in general and therapeutic potential in patients with $\mathrm{CAD}$ in particular. However further studies need to be done including clinical trials for further exploration of the medicinal prospects of garlic extract.

Funding: None

Conflict of interests: None declared

Ethical approval: Approved by the Institutional Animal Ethics Committee

\section{REFERENCS}

1. Brodia A, Arora SK, Rathore BS, Bhu N. Essential oil of garlic on blood lipids and fibrinolytic activity in patients of coronary artery disease. J Assoc Physicians India 1978;26:327-31.

2. Prevention of coronary heart disease. Report of a WHO Expert Committee. WHO, Geneva. Tech. Rep. Ser.1982;678.

3. Gordon T, Castelli WP, Hijorland MC, Kannel WB, Dawber TR. High density lipoprotein as a protective factor against coronary artery disease. The Framingham Study. Am J Med. 1977;62:707-14.
4. Kastelein JJP. The realities of dyslipidaemia: what do the studies tell us? Eur Heart J Suppl. 2005;7:F27-33.

5. Anitschkow N, Chatalaw O' Ober. Experimentalle Cholesterinsteatose undihre Boden tungfur die entstenung einger. Pathologist Cher Prozessess Centrabe, All Path. Anat 1913;24:1.

6. Hunninghake DB and Probstfield JL Drug Treatment of hyperlipoproteinemia. In Hyperlipidemia: Diagnosis and therapy (Rifkind BM, And Levy RI.eds) Grunne and Stratton, Inc New York 1977; 327-62.

7. National Cholesterol Education Program. Executive Summary of third report of the National Cholesterol Education program expert panel on detection, evaluation and treatment of high blood cholesterol in adults (Adult treatment panel III). JAMA 2001;285(19):2486-97.

8. Scandinavian Simvastatin Survival Study. Randomized controlled Trial of Cholesterol lowering 4444 patients with Coronary Heart Disease: The 4S Study. Lancet 1994;344:1383-9.

9. Omar MA, Wilson JP, Cox TS. Rhabdomyolysis and HMG CoA-Reductase inhibitor. Ann. Pharmacother 2001;35:1096-107.

10. Warren CPW. Some aspects of medicine in the greek bronze age. J Med Hist 1970;14:364-77.

11. Hindjo, Pilar Herrero and France MC. Biol Soc Espan Hist Farm 1968;19(73).

12. Srivastava KC, Bordia A, Verma SK. Garlic (Allium sativum) for disease prevention. South African J Science 1995;91:68-77.

13. Barness J, Anderson LA, Phillipson JD, eds. Garlic. In: Herbal medicines. 2nd ed. London: Pharmaceutical Press 2002;226-40.

14. Bordia A. Effect of garlic on blood lipids in patients with coronary heart disease. Am J Clin Nutr 1981;34:2100-3.

15. Ali M, Thromson M. Consumption of a garlic clove a day could be beneficial in preventing thrombosis. Prostaglandins. Leukot Essent Fatty Acids 1995;53:211-12.

16. Bordia A, Verma SK. Effect of garlic feeding on regression of experimental atherosclerosis in rabbits. Artery 1980;7:428-37.

17. Brodia A, Arora SK, Kothari LK, Jain KC, Rathore BS, Rathore AS, Dube MK, Bhu N. The protective action of essential oil of garlic in cholesterol fed rabbits. Atherosclerosis 1975;22:103-9.

18. Sainani GS, Pesai DB. Indian J Med Res 1979;7:776-80.

19. Koch HP, Lawson LD. Garlic: the science and therapeutic application of Allium sativum L. And related species. $2^{\text {nd }}$ ed. Baltimore: Williams \& Wilkins, 1996.

20. Warshafsky S, Kamer RS, Sivak SL. Effect of garlic on total serum cholesterol. A meta-analysis. Ann Intern Med 1993;119(7):599-605. 
21. Silagy C, Neil A. Garlic as a lipid lowering agent -a Meta analysis. J.R. Coll Physicians Lond 1994;28:39-45.

22. Ackerman RT, Murlow CD, Ramirez G, Gardner CD, Morbidoni L, Lawrence VA. Garlic shows promise for improving some cardiovascular risk factors. Arch Intern Med 2001;161:813-24.
23. Carrol KK. Plasma cholesterol and liver cholesterol biosynthesis in rabbits fed commercial or semisynthetic diets with or without added fat or oils. Atherosclerosis 1971;13:67-76.

doi:10.5455/2319-2003.ijbcp20130810

Cite this article as: Dalal I, Sengupta M, Paul S, Mishra AN. Comparative study of the effect of atorvastatin and garlic extract in experimentally induced hypercholesterolemia in rabbits. Int $\mathrm{J}$ Basic Clin Pharmacol 2013;2:397-402. 